\title{
Penggunaan kalium nitrat dalam pematahan dormansi fisiologis setelah pematangan pada beberapa galur padi mutan organik spesifik lokal Aceh
}

Sari. Induksi mutasi radiasi merupakan metode efektif untuk meningkatkan keragaman tanaman. Kajian akan sifat-sifat yang dibawa oleh generasi galur padi hasil mutasi penting untuk dipelajari. Penelitian ini bertujuan untuk mengetahui pengaruh radiasi sinar gamma terhadap sifat dormansi fisiologis after ripening pada galur padi mutan organik dan mengetahui keefektifan penggunaan konsentrasi $\mathrm{KNO}_{3}$ terhadap upaya pematahan dormansinya. Penelitian dilaksanakan di Laboratorium Ilmu dan Teknologi Benih, Fakultas Pertanian, Universitas Syiah Kuala. Penelitian ini menggunakan Rancangan Acak Lengkap (RAL) pola faktorial dengan dua faktor serta menggunakan uji lanjut Tukey pada taraf nyata $5 \%$. Faktor pertama adalah galur padi mutan organik terdiri 5 taraf yaitu $\mathrm{G}_{0}=$ tanpa radiasi (Sanbei Simeleu) sebagai pembanding, $\mathrm{G}_{1}=$ Sultan Unsrat, $\mathrm{G}_{2}=39 \mathrm{e}, \mathrm{G}_{3}=75 \mathrm{~d}, \mathrm{G}_{4}=57 \mathrm{e}$. Faktor kedua adalah konsentrasi $\mathrm{KNO}_{3}$ terdiri 3 taraf yaitu $\mathrm{K}_{0}=0 \%, \mathrm{~K}_{1}=1 \%$, dan $\mathrm{K}_{2}=2 \%$. Parameter yang diamati adalah potensi tumbuh maksimum, daya berkecambah, indeks vigor, keserempakan tumbuh, kecepatan tumbuh relatif, berat kering kecambah normal, dan persistensi dormansi. Hasil penelitian menunjukkan bahwa galur padi mutan organik berpengaruh sangat nyata terhadap berat kering kecambah normal dan berpengaruh nyata terhadap potensi tumbuh maksimum. Konsentrasi $\mathrm{KNO}_{3}$ berpengaruh sangat nyata terhadap daya berkecambah dan berat kering kecambah normal, serta berpengaruh nyata terhadap potensi tumbuh maksimum dan kecepatan tumbuh relatif. Terdapat interaksi sangat nyata antara galur padi mutan organik dan konsentrasi $\mathrm{KNO}_{3}$ terhadap berat kering kecambah normal, dan interaksi nyata terhadappotensi tumbuh maksimum, dan daya berkecambah. Kombinasi terbaik dijumpai pada galur padi mutan organik 57e dan konsentrasi $\mathrm{KNO}_{3} 2 \%$.

Kata kunci: Setelah pematangan $\cdot$ Dormansi $\cdot$ Galur mutan $\cdot \mathrm{KNO}_{3} \cdot$ Padi

\section{Potassium nitrate for breaking the physiological dormancy after ripening in several specific organic local mutant rice lines from Aceh}

\begin{abstract}
This study aims to determine the effect of gamma radiation on the physiological dormancy afterripening of organic mutant rice lines and the effectiveness using $\mathrm{KNO}_{3}$ concentrations on efforts to break dormancy. The study was conducted at the Seed Science and Technology Laboratory, Syiah Kuala University. This research used a completely randomized design (CRD) with two factors and Tukey test at significance level of $5 \%$. The first factor was the organic mutant rice lines that consisted of 5 levels. There were $\mathrm{G}_{0}=$ without radiation (Sanbei Simeleu) as a comparison, $\mathrm{G}_{1}=$ Sultan Unsrat, $\mathrm{G}_{2}=39 \mathrm{e}, \mathrm{G}_{3}=75 \mathrm{~d}$, and $\mathrm{G}_{4}=57 \mathrm{e}$. The second factor was $\mathrm{KNO}_{3}$ concentration, that consisted of 3 levels. There were $\mathrm{K}_{0}=0 \%, \mathrm{~K}_{1}=$ $1 \%$, and $\mathrm{K}_{2}=2 \%$. The observed parameters were dormancy persistence, maximum growth potential, germination, vigour index, the simultaneity of growth, relative growth speed, and normal germination dry weight,. The results showed that the organic mutant rice lines had a very significant effect on the dry weight of normal sprouts and had a significant effect on maximum growth potential. $\mathrm{KNO}_{3}$ concentration has a very significant effect on germination and dry weight of normal sprouts and has a significant effect on the maximum growth potential and relative growth speed. There was a highly significant interaction between organic mutant rice lines and $\mathrm{KNO}_{3}$ concentration on the normal dry weight of the sprouts, and significant interaction with maximum growth potential and germination. The best interaction was found in organic mutant rice lines 57e and $\mathrm{KNO}_{3}$ concentration of $2 \%$.
\end{abstract}

Keywords: After ripening $\cdot$ Dormancy $\cdot \mathrm{KNO}_{3} \cdot$ Mutantline $\cdot$ Rice

Diterima : 1 Januari 2020, Disetujui : 21 Maret 2020, Dipublikasikan : 31 Maret 2020 doi: https://doi.org/10.24198/ kultivasi.v19i1.25468 


\section{Pendahuluan}

Perbaikan sifat tanaman, secara kualitatif dan kuantitatif, dapat dilakukan melalui pemuliaan tanaman. Tujuannya adalah untuk menghasilkan galur baru atau varietas tanaman dengan sifat-sifat (morfologi, fisiologi, biokimia, dan agronomi) yang sesuai dengan sistem budidaya dan manfaat ekonomi yang diinginkan. Pemuliaan tanaman akan berhasil jika dalam populasi tersebut terdapat banyak variasi genetik. Variasi genetik dapat diperoleh dengan cara koleksi, introduksi, hibridisasi, dan induksi mutasi (Crowder, 1986). Pemuliaan tanaman konvensional dilakukan dengan hibridisasi, sedangkan pemuliaan mutasi dapat diinduksi dengan mutagen fisik atau mutagen kimia. Umumnya mutagen fisik menyebabkan mutasi pada tahap kromosom, sedangkan mutagen kimia menyebabkan mutasi pada tahapan gen atau basa nitrogen (Aisyah et al., 2009).

Mutasi adalah proses perubahan mendadak materi genetik dari sel, mencakup perubahan pada tingkat gen, molekuler, atau kromosom. Induksi mutasi merupakan salah satu metode yang efektif untuk meningkatkan keragaman tanaman. Mutasi gen terjadi sebagai akibat perubahan dalam gen dan timbul secara spontan. Gen yang berubah karena mutasi disebut mutan (Poehlman dan Sleper, 2006).

Pengembangan galur padi mutan baru hasil seleksi radiasi gamma masih memerlukan kajian yang panjang. Respon fisiologis akibat radiasi memberikan dampak terhadap benih. Beberapa varietas dan galur padi umumnya memiliki dormansi benih yang dapat berpengaruh terhadap ketersediaan benih pada saat diperlukan.

Dormansi benih padi terjadi sejak benih masih berada pada tanaman induk, setelah embrio berkembang disebut sebagai dormansi primer atau innate dormancy. Penyebab dormansi primer yang terjadi pada benih padi adalah after ripening yang mempunyai peranan dalam rendahnya nilai perkecambahan benih padi. Benih yang mengalami after ripening akan berkecambah bila disimpan dalam jangka waktu tertentu. Periode after-ripening beragam dari 0-11 minggu. Varietas padi yang berumur pendek atau genjah (100-115 hari) tidak selalu memiliki periode after-ripening yang pendek (Kharismayani, 2010).

Dormansi fisiologis akibat after-ripening dapat dipatahkan dengan perlakuan suhu tinggi, pengupasan kulit, dan perendaman pada larutan kimia baik larutan organik maupun larutan anorganik. Dormansi yang disebabkan oleh faktor fisiologis dapat dipatahkan dengan penyimpanan kering, pre-chilling, preheating, cahaya, $\mathrm{KNO}_{3}$, dan asam giberelat $\left(\mathrm{GA}_{3}\right)$ (ISTA,1999). Salah satu upaya pematahan dormansi dapat dilakukan dengan cara kimiawi yaitu menggunakan kalium nitrat $\left(\mathrm{KNO}_{3}\right)$. Perendaman benih ke dalam zat kimia dapat memacu aktivitas enzim untuk melakukan perombakan cadangan makanan pada benih. Larutan $\mathrm{KNO}_{3}$ diketahui memiliki stimulator effect terhadap perkecambahan benih. Larutan $\mathrm{KNO}_{3}$ berfungsi menstimulir perkecambahan khususnya pada benih-benih yang peka terhadap cahaya. Perlakuan $\mathrm{KNO}_{3}$ akan efektif pada jenis benih ortodoks. Larutan $\mathrm{KNO}_{3}$ juga dapat meningkatkan peran giberalin dalam perkecambahan benih. Efek $\mathrm{KNO}_{3}$ yang ditimbulkan pada benih ditentukan oleh besar kecil konsentrasinya (Santika, 2006).

Efektifitas $\mathrm{KNO}_{3}$ dalam mematahkan dormansi benih berhubungan dengan peningkatan ketersediaan $\mathrm{O}_{2}$ untuk memperlancar mekanisme lintasan pentosa fosfat. Ketersediaan $\mathrm{O}_{2}$ yang terbatas dapat mengakibatkan tidak aktifnya lintasan pentosa fosfat karena $\mathrm{O}_{2}$ lebih banyak digunakan untuk aktivitas respirasi melalui lintasan lain. Disamping itu akseptor hidrogen seperti nitrat yang berasal dari $\mathrm{KNO}_{3}$ diduga juga berperan dalam proses reoksidasi NADPH untuk meningkatkan aktivitas lintasan pentosa fosfat (Khan (1977).

Untuk mengatasi masalah ini diperlukan metode pematahan dormansi yang efektif untuk dapat meningkatkan validitas hasil pengujian daya berkecambah dan mengatasi masalah dormansi pada saat benih diperlukan untuk segera ditanam. Pematahan dormansi dikatakan efektif apabila menghasilkan daya berkecambah $85 \%$ atau lebih. Berdasarkan uraian diatas, maka perlu dilakukan penelitian tentang efektivitas konsentrasi $\mathrm{KNO}_{3}$ terhadap pematahan dormansi benih pada beberapa galur padi hasil seleksi radiasi gamma. Tujuan penelitian ini untuk mempelajari dan mendapatkan data mengenai sifat dormansi after ripening pada galur benih padi mutan sebelum dilepaskan menjadi varietas unggul baru. 


\section{Metode Penelitian}

Penelitian ini dilaksanakan di Laboratorium Ilmu dan Teknologi Benih Fakultas Pertanian Universitas Syiah Kuala pada Februari 2018 hingga November 2018.

Penelitian ini menggunakan Rancangan Acak Lengkap pola faktorial. Terdiri atas 2 faktor dan 3 ulangan. Faktor pertama adalah jenis galur padi $(G)$, ada 5 taraf yaitu: $G_{0}=$ galur tanpa radiasi (Sanbei Siemelu) sebagai pembanding, $G_{1}=$ Sultan Unstrat $, G_{2}=39 \mathrm{e}, \mathrm{G}_{3}=$ 75 d, dan $\mathrm{G}_{4}=57$ e. Faktor kedua yaitu konsentrasi $\mathrm{KNO}_{3}(\mathrm{~K})$, ada 3 taraf yaitu $\mathrm{K}_{0}=0 \%$, $K_{1}=1 \%$, dan $K_{2}=2 \%$. Dengan demikian terdapat 15 kombinasi perlakuan. Tiap kombinasi perlakuan diulang $3 \mathrm{kali}$, sehingga terdapat 45 satuan percobaan. Apabila uji F pada taraf nyata menunjukkan pengaruh nyata, maka dilanjutkan dengan uji Beda Nyata Jujur (Tukey) pada taraf nyata $5 \%$.

Pelaksanaan Penelitian. Benih padi direndam dalam larutan $\mathrm{KNO}_{3}$ dengan konsentrasi $0 \%$, $1 \%$ dan $2 \%$. Kebutuhan $\mathrm{KNO}_{3}$ pada konsentrasi 1\% (10 g), dan 2\% (20 g), ditambahkan dengan aquades hingga mencapai 1 L, kemudian diaduk hingga larut. Benih dimasukkan ke dalam beackerglass $600 \mathrm{ml}$ selama 24 jam pada suhu $28^{\circ} \mathrm{C}$, untuk menjaga $\mathrm{O}_{2}$ dalam larutan tetap tersedia maka digunakan aerator.

Benih yang telah direndam, dicuci pada air mengalir dan dikeringanginkan selama 1×24 jam. Selanjutnya dikecambahkan menggunakan media kertas merang dengan metode uji UKDdp (Uji Kertas Digulung dalam plastik) dan untuk setiap satuan percobaan berisi 25 butir benih dan ditempatkan dalam germinator.

Parameter Pengamatan. Parameter yang diamati adalah parameter dormansi, viabilitas, dan vigor benih. Viabilitas diukur berdasarkan potensi tumbuh maksimum dan daya berkecambah, sedangkan vigor diukur berdasarkan indeks vigor, kecepatan tumbuh relatif, keserempakan tumbuh, dan berat kering kecambah normal. Parameter dormansi diukur berdasarkan persistensi dormansi.

Persistensi Dormansi (minggu). Persistensi dormansi adalah periode simpan pada suhu kamar yang diperlukan benih dari saat panen sampai persentase benih non-dormannya mencapai $85 \%$ atau lebih. Tolok ukur persistensi dormansi dinyatakan dalam minggu. Metode penentuan persistensi dormansi didasarkan pada grafik linier hubungan antara daya berkecambah dengan periode after-ripening setiap minggu

Potensi Tumbuh Maksimum (\%). Potensi tumbuh maksimum menggambarkan gejala tumbuh benih hingga pengamatan hari ke-14 setelah tanam (final count). Benih berkecambah bila telah muncul akar atau plumula menembus kulit benih (pericarp).

Daya Berkecambah (\%). Daya berkecambah menggambarkan viabilitas potensial benih, dihitung berdasarkan persentase kecambah normal pada 7 hari setelah tanam (first count) dan 14 hari setelah tanam (final count).

Indeks Vigor. Indeks vigor menggambarkan vigor kekuatan tumbuh benih (Copeland dan McDonald, 2001), dihitung berdasarkan persentase kecambah normal pada hari ke-7 (first count).

Kecepatan Tumbuh Relatif (\%). Kecepatan tumbuh menggambarkan vigor benih, yaitu perbandingan nilai $\mathrm{K}_{\mathrm{CT}}$ dengan $\mathrm{K}_{\mathrm{CT}}$ maksimum. Pengamatan dilakukan setiap hari selama waktu perkecambahan 14 hari.

Keserempakan Tumbuh (\%). Keserempakan tumbuh menggambarkan vigor kekuatan tumbuh benih, dihitung berdasarkan persentase kecambah normal pada hari ke 10, yaitu antara hitungan pertama (7 hari setelah tanam/HST) dan kedua (14 HST)

Berat Kering Kecambah Normal (mg). Berat kering kecambah normal ditentukan dengan cara semua benih yang berkecambah normal dikeringkan terlebih dahulu menggunakan oven suhu $60^{\circ} \mathrm{C}$ selama $3 \times 24$ jam lalu ditimbang beratnya.

\section{Hasil dan Pembahasan}

Hasil Penelitian. Persistensi dormansi dari masing masing galur disajikan pada Tabel 1. Galur yang memiliki periode after ripening paling pendek dijumpai pada galur Sultan Unsrat, 39e, dan 57e yaitu tiga minggu setelah panen. Galur $75 \mathrm{~d}$ periode dormansinya terpatahkan pada minggu ke-4. Galur Sanbei Simeulu dormansi baru mengalami pematahan pada minggu ke-8.

Hasil analisis ragam, perlakuan galur padi mutan berpengaruh sangat nyata terhadap berat kering kecambah normal, berpengaruh nyata terhadap potensi tumbuh maksimum tetapi berpengaruh tidak nyata terhadap daya 
berkecambah, indeks vigor, keserempakan kecepatan tumbuh relatif, dan keserempakan tumbuh. Rata-rata nilai viabilitas dan vigor benih padi pada beberapa galur padi mutan tersaji pada Tabel 2.

Tabel 1. Persistensi dormansi benih galur padi mutan berdasarkan hasil uji daya berkecambah.

\begin{tabular}{|c|c|c|c|c|c|}
\hline \multirow{2}{*}{$\begin{array}{l}\text { Lama } \\
\text { simpan } \\
\text { setelah } \\
\text { panen } \\
\text { (Minggu) }\end{array}$} & \multicolumn{5}{|c|}{ Daya berkecambah (\%) } \\
\hline & $\begin{array}{c}\text { Sanbei } \\
\left(G_{0}\right)\end{array}$ & $\begin{array}{c}\text { Sultan } \\
\text { Unsrat } \\
\left(\mathrm{G}_{1}\right)\end{array}$ & $\begin{array}{l}39 \mathrm{e} \\
\left(\mathrm{G}_{2}\right)\end{array}$ & $\begin{array}{l}75 d \\
\left(G_{3}\right)\end{array}$ & $\begin{array}{l}57 \mathrm{e} \\
\left(\mathrm{G}_{4}\right)\end{array}$ \\
\hline 1 & 20 & 70 & 4 & 28 & 32 \\
\hline 2 & 28 & 80 & 8 & 48 & 76 \\
\hline 3 & 56 & 100 & 92 & 84 & 92 \\
\hline 4 & 81 & - & - & 95 & - \\
\hline 5 & 81 & - & - & - & - \\
\hline 6 & 81 & - & - & - & - \\
\hline 7 & 82 & - & - & - & - \\
\hline 8 & 90 & - & - & - & - \\
\hline $\begin{array}{l}\text { Persistensi } \\
\text { dormansi } \\
\text { (Minggu) }\end{array}$ & 8 & 3 & 3 & 4 & 3 \\
\hline
\end{tabular}

Keterangan: Dormansi pada benih padi terpatahkan apabila persentase perkecambahan mencapai angka $85 \%$.

Hasil analisis ragam menyatakan bahwa konsentrasi $\mathrm{KNO}_{3}$ berpengaruh sangat nyata terhadap daya berkecambah dan berat kering kecambah normal, berpengaruh nyata terhadap potensi tumbuh maksimum dan kecepatan tumbuh relatif, tetapi tidak berpengaruh nyata terhadap indeks vigor dan keserempakan tumbuh. Rata-rata parameter viabilitas dan vigor galur padi mutan terhadap konsentrasi $\mathrm{KNO}_{3}$ tersaji pada Tabel 3.

Hasil penelitian menyebutkan interaksi antara perlakuan galur mutan dan konsentrasi $\mathrm{KNO}_{3}$ berpengaruh sangat nyata terhadap berat kering kecambah normal, berpengaruh nyata terhadap potensi tumbuh maksimum dan daya berkecambah, namun tidak berpengaruh nyata terhadap berat kering kecambah normal (BKKN), keserempakan kecepatan tumbuh relatif dan keserempakan tumbuh. Rata-rata nilai potensi tumbuh maksimum, daya berkecambah dan BKKN akibat beberapa galur benih padi dengan taraf konsentrasi $\mathrm{KNO}_{3}$ dapat dilihat pada Tabel 4.

Tabel 4 menunjukkan bahwa peningkatan konsentrasi $\mathrm{KNO}_{3}$ dapat menyebabkan penurunan potensi tumbuh maksimum galur padi mutan. Nilai potensi tumbuh maksimum tertinggi diperoleh pada galur 57e pada konsentrasi $\mathrm{KNO}_{3} 0 \%$, yaitu 98,67\%, sedangkan nilai potensi tumbuh maksimum terendah diperoleh pada galur Sanbei Siemelu pada konsentrasi $\mathrm{KNO}_{3} 2 \%$, yaitu $85,33 \%$. Daya berkecambah galur padi mutan menurun dengan penambahan konsentrasi $\mathrm{KNO}_{3}$. Daya kecambah lebih tinggi diperoleh pada galur Sanbei Siemelu pada konsentrasi $\mathrm{KNO}_{3} 0 \%$, yaitu $90,67 \%$, sedangkan daya kecambah terendah diperoleh pada galur yang sama dengan $\mathrm{KNO}_{3} 2 \%$, yaitu $77,33 \%$. Berat kering kecambah normal galur padi mutan pada konsentrasi $\mathrm{KNO}_{3} 1 \%$ menyebabkan penurunan

Tabel 2. Rata-rata parameter viabilitas dan vigor benih padi pada beberapa galur padi mutan.

\begin{tabular}{|c|c|c|c|c|c|c|}
\hline \multirow[b]{2}{*}{ Perlakuan } & \multicolumn{6}{|c|}{ Nilai viabilitas dan vigor benih } \\
\hline & PTM $(\%)$ & $\mathrm{DB}(\%)$ & $\mathrm{K}_{\mathrm{ST}}(\%)$ & IV $(\%)$ & $\mathrm{K}_{\mathrm{CT}-\mathrm{R}}(\%)$ & $\begin{array}{c}\text { BKKN } \\
\text { (mg) }\end{array}$ \\
\hline $\begin{array}{l}\text { Sanbei Siemelu } \\
\left(\mathrm{G}_{0}\right)\end{array}$ & 91,56 a & 84,00 & $\begin{array}{c}70,22 \\
(57,10)\end{array}$ & $\begin{array}{c}42,67 \\
(40,43)\end{array}$ & $\begin{array}{c}77,77 \\
(61,95)\end{array}$ & $\begin{array}{c}0,06 \\
(0,74) \mathrm{a}\end{array}$ \\
\hline $\begin{array}{c}\text { Sultan Unsrat } \\
\left(\mathrm{G}_{1}\right)\end{array}$ & $94,22 \mathrm{ab}$ & 86,22 & $\begin{array}{c}75,11 \\
(60,40)\end{array}$ & $\begin{array}{c}55,11 \\
(48,03)\end{array}$ & $\begin{array}{c}83,69 \\
(66,63)\end{array}$ & $\begin{array}{c}0,09 \\
(0,77) \mathrm{ab}\end{array}$ \\
\hline $39 \mathrm{e}\left(\mathrm{G}_{2}\right)$ & $93,78 \mathrm{ab}$ & 86,78 & $\begin{array}{c}68,44 \\
(55,92)\end{array}$ & $\begin{array}{c}48,89 \\
(44,36)\end{array}$ & $\begin{array}{c}80,35 \\
(63,72)\end{array}$ & $\begin{array}{c}0,14 \\
(0,80) \mathrm{ab}\end{array}$ \\
\hline $75 \mathrm{~d}\left(\mathrm{G}_{3}\right)$ & $94,67 \mathrm{ab}$ & 86,67 & $\begin{array}{c}65,33 \\
(54,10)\end{array}$ & $\begin{array}{c}47,56 \\
(43,58)\end{array}$ & $\begin{array}{c}78,67 \\
(62,86)\end{array}$ & $\begin{array}{c}0,13 \\
(0,79) \mathrm{ab}\end{array}$ \\
\hline 57e $\left(\mathrm{G}_{4}\right)$ & $96,89 \mathrm{~b}$ & 88,44 & $\begin{array}{c}72,00 \\
(58,41)\end{array}$ & $\begin{array}{c}46,67 \\
(43,08)\end{array}$ & $\begin{array}{c}82,45 \\
(65,34)\end{array}$ & $\begin{array}{c}0,20 \\
(0,83) \mathrm{b}\end{array}$ \\
\hline BNJ 5\% & 4,55 & - & - & - & - & 0,12 \\
\hline
\end{tabular}

Keterangan: Angka yang diikuti oleh huruf yang berbeda pada kolom yang sama menunjukkan berbeda nyata pada taraf nyata 0,05 (Uji BNJ). Angka yang berada di dalam tanda kurung adalah angka transformasi $\arcsin \sqrt{y}$. PTM: potensi tumbuh maksimum; DB: daya berkecambah; IV: indeks vigor; $\mathrm{K}_{\mathrm{CT}}-\mathrm{R}$ : kecepatan tumbuh relatif; $\mathrm{K}_{\mathrm{ST}}$ : keserempakan tumbuh; BKKN: berat kering kecambah normal. 
Tabel 3. Rata-rata parameter viabilitas dan vigor galur padi mutan pada berbagai konsentrasi $\mathrm{KNO}_{3}$

\begin{tabular}{|c|c|c|c|c|c|c|}
\hline \multirow{2}{*}{$\begin{array}{l}\text { Konsentrasi } \\
\mathrm{KNO}_{3}(\%)\end{array}$} & \multicolumn{6}{|c|}{ Parameter viabilitas dan vigor benih } \\
\hline & PTM (\%) & DB (\%) & $\mathrm{K}_{\mathrm{ST}}(\%)$ & IV $(\%)$ & $\mathrm{K}_{\mathrm{CT}-\mathrm{R}}(\%)$ & BKKN (mg) \\
\hline $0 \%\left(\mathrm{~K}_{0}\right)$ & $96,53 \mathrm{~b}$ & $88,80 \mathrm{~b}$ & $\begin{array}{c}72,27 \\
(58,61)\end{array}$ & $\begin{array}{c}50,13 \\
(44,96)\end{array}$ & $\begin{array}{c}83,28 \\
(66,27) \mathrm{b}\end{array}$ & $\begin{array}{c}0,22 \\
(0,85) \text { c }\end{array}$ \\
\hline $1 \%\left(\mathrm{~K}_{1}\right)$ & $93,60 \mathrm{ab}$ & 85,60 a & $\begin{array}{c}70,13 \\
(57,08)\end{array}$ & $\begin{array}{c}48,80 \\
(44,29)\end{array}$ & $\begin{array}{c}80,34 \\
(63,79) \mathrm{ab}\end{array}$ & $\begin{array}{c}0,15 \\
(0,81) b\end{array}$ \\
\hline $2 \%\left(K_{2}\right)$ & 92,53 a & 84,27 a & $\begin{array}{c}68,27 \\
(55,86)\end{array}$ & $\begin{array}{c}45,60 \\
(42,44)\end{array}$ & $\begin{array}{c}78,14 \\
(62,25) \mathrm{a}\end{array}$ & $\begin{array}{c}0,00 \\
(0,71) \mathrm{a}\end{array}$ \\
\hline BNJ 0,05 & 3,00 & 2,79 & - & - & 3,28 & 0,10 \\
\hline
\end{tabular}

Keterangan: Angka yang diikuti oleh huruf yang berbeda pada kolom yang sama menunjukkan berbeda nyata pada Taraf 0,05 (Uji BNJ). Angka yang berada di dalam tanda kurung adalah angka transformasi $\arcsin \sqrt{y}$.

Tabel 4. Interaksi antara galur mutan dan konsentrasi $\mathrm{KNO}_{3}$ terhadap potensi tumbuh maksimum, daya berkecambah, dan berat kering kecambah normal.

\begin{tabular}{|c|c|c|c|}
\hline \multirow[t]{2}{*}{ Galur } & \multicolumn{3}{|c|}{$\begin{array}{l}\text { Potensi tumbuh maksimum (\%) } \\
\text { Konsentrasi } \mathrm{KNO}_{3}\end{array}$} \\
\hline & $0 \%\left(\mathrm{~K}_{0}\right)$ & $1 \%\left(\mathrm{~K}_{1}\right)$ & $2 \%\left(K_{2}\right)$ \\
\hline Sanbei Siemelu $\left(\mathrm{G}_{0}\right)$ & $97,33 \mathrm{Ba}$ & $92.00 \mathrm{Aba}$ & $85.33 \mathrm{Aa}$ \\
\hline Sultan Unsrat $\left(\mathrm{G}_{1}\right)$ & $96,00 \mathrm{Aa}$ & $92.00 \mathrm{Aa}$ & 94.67 Aab \\
\hline $39 \mathrm{e}\left(\mathrm{G}_{2}\right)$ & $94,67 \mathrm{Aa}$ & $92.00 \mathrm{Aa}$ & 94.67 Aab \\
\hline $75 \mathrm{~d}\left(\mathrm{G}_{3}\right)$ & $96,00 \mathrm{Aa}$ & $97.33 \mathrm{Aa}$ & $90.67 \mathrm{Aab}$ \\
\hline $57 \mathrm{e}\left(\mathrm{G}_{4}\right)$ & $98,67 \mathrm{Aa}$ & $94.67 \mathrm{Aa}$ & $97.33 \mathrm{Ab}$ \\
\hline \multirow[t]{3}{*}{ BNJ $5 \%$} & & 9,98 & \\
\hline & \multicolumn{3}{|c|}{ Daya berkecambah (\%) } \\
\hline & $0 \%\left(\mathrm{~K}_{0}\right)$ & $1 \%\left(\mathrm{~K}_{1}\right)$ & $2 \%\left(\mathrm{~K}_{2}\right)$ \\
\hline Sanbei Siemelu $\left(\mathrm{G}_{0}\right)$ & $90.67 \mathrm{Ba}$ & $84.00 \mathrm{Aba}$ & $77.33 \mathrm{Aa}$ \\
\hline Sultan Unsrat $\left(\mathrm{G}_{1}\right)$ & $88.00 \mathrm{Aa}$ & $84.00 \mathrm{Aa}$ & $86.67 \mathrm{Ab}$ \\
\hline $39 \mathrm{e}\left(\mathrm{G}_{2}\right)$ & $86.67 \mathrm{Aa}$ & $84.00 \mathrm{Aa}$ & $86.67 \mathrm{Ab}$ \\
\hline $75 \mathrm{~d}\left(\mathrm{G}_{3}\right)$ & $88.00 \mathrm{Aa}$ & $89.33 \mathrm{Aa}$ & 82.67 Aab \\
\hline $57 \mathrm{e}\left(\mathrm{G}_{4}\right)$ & $90.67 \mathrm{Aa}$ & $86.67 \mathrm{Aa}$ & $88.00 \mathrm{Ab}$ \\
\hline \multirow{3}{*}{ BNJ 5\% } & & 9.32 & \\
\hline & \multicolumn{3}{|c|}{ Berat Kering Kecambah Normal (mg) } \\
\hline & $0 \%\left(\mathrm{~K}_{0}\right)$ & $1 \%\left(\mathrm{~K}_{1}\right)$ & $2 \%\left(\mathrm{~K}_{2}\right)$ \\
\hline Sanbei Siemelu $\left(\mathrm{G}_{0}\right)$ & $0.80 \mathrm{Aa}$ & $0.72 \mathrm{Aa}$ & $0.71 \mathrm{Aa}$ \\
\hline Sultan Unsrat $\left(\mathrm{G}_{1}\right)$ & $0.81 \mathrm{Aa}$ & $0.79 \mathrm{Aa}$ & $0.71 \mathrm{Aa}$ \\
\hline $39 \mathrm{e}\left(\mathrm{G}_{2}\right)$ & $0.85 \mathrm{Aa}$ & $0.83 \mathrm{Aa}$ & $0.71 \mathrm{Aa}$ \\
\hline $75 \mathrm{~d}\left(\mathrm{G}_{3}\right)$ & $0.87 \mathrm{Aa}$ & $0.79 \mathrm{Aa}$ & $0.71 \mathrm{Aa}$ \\
\hline 57e $\left(\mathrm{G}_{4}\right)$ & $0.89 \mathrm{Aab}$ & $0.89 \mathrm{Aab}$ & $0.71 \mathrm{Aa}$ \\
\hline BNJ $5 \%$ & & 0.30 & \\
\hline
\end{tabular}

Keterangan : Angka yang diikuti oleh huruf yang sama (huruf besar menurut baris dan huruf kecil menurut kolom) berbeda tidak nyata pada taraf 0,05 (Uji BNJ)

daya kecambah benih padi galur padi tersebut, meskipun secara statistik berbeda tidak nyata dengan konsentrasi $\mathrm{KNO}_{3} 2 \%$. Berat kering kecambah normal cenderung lebih tinggi diperoleh pada galur 57e dengan pemberian $\mathrm{KNO}_{3} 0 \%$ dan $1 \%$, yaitu $0,89 \mathrm{mg}$.

\section{Hasil dan Pembahasan}

Periode persistensi dormansi berbeda-beda yang disebabkan faktor spesies, musim tanam, verietas, lokasi panen dan faktor perkembangan benih itu sendiri (Ooi et al., 2007). Perbedaan viabilitas benih disebabkan adanya perbedaan genetik tiap galur yang dicobakan. Sejalan dengan pendapat Bewley dan Black (1985), yaitu persistensi dormansi dari tetua betina tergolong tinggi. Sifat dormansi menurun melalui mekanisme maternal effect. Sifat dormansi benih padi dikendalikan oleh gen kuantitatif yang kumulatif namun efeknya berbeda untuk setiap varietas dan lamanya periode dormansi benih juga dipengaruhi oleh 
faktor lingkungan (Gu et al., 2003). Perbedaan persistensi dormansi antar kultivar juga berkaitan dengan faktor yang mempengaruhi masa dormansi. Panjang pendeknya masa dormansi benih padi berhubungan dengan banyaknya asam lemak jenuh berantai pendek, tingkat impermeabilitas kulit benih terhadap air atau oksigen, dan banyak sedikitnya kandungan zat penghambat perkecambahan (Khan, 1977). Persistensi dormansi padi digolongkan menjadi tiga kelompok, yaitu padi yang memiliki persistensi pendek (kurang dari 4 minggu), persistensi sedang (4-8 minggu) dan persistensi panjang (lebih dari 8 minggu) (Nugraha dan Soejadi, 2001). Berdasarkan kriteria tersebut maka padi Sanbei Simeulu digolongkan kedalam persistensi panjang, galur mutan $75 \mathrm{~d}$ tergolong persistensi sedang dan galur Sultan Unstrat, 39e, 57e tergolong persistensi pendek. Hal ini berarti, pemberian radiasi pada benih mutan dalam upaya mendapatkan sifat yang lebih baik dari varietas asalnya telah tercapai dengan semakin pendeknya persistensi dormansi benih galur mutan.

Copeland dan Donald (2001) membedakan dormansi menjadi dua tipe yaitu dormansi primer dan sekunder. Dormansi primer disebabkan dari dalam benih, sedangkan dormansi sekunder diakibatkan dari faktor lingkungan. Dormansi primer dibagi menjadi dua jenis yaitu dormansi primer eksogenus dan endogenous. Dormansi eksogeneus yaitu dormansi yang berkaitan dengan sifat fisik dari kulit. Terdapat pembatasan secara struktural dengan perkecambahan oleh kulit yang keras dan kedap terhadap air dan gas yang disebabkan oleh impermeabelitas kulit biji, resistensi mekanisme kulit biji terhadap perubahan embrio serta zat inhibitor (penghambat). Dormansi endogenous yaitu dormansi yang terjadi karena beberapa sifat yang melekat pada benih, seperti embrio yang rudimenter serta irritabilitas terhadap cahaya dan suhu.

Kondisi lingkungan selama pertumbuhan dan pembungaan benih juga dapat mempengaruhi lamanya durasi dormansi endogenus. Faktor lingkungan yang mempengaruhi dormansi endogenus diantaranya adalah panjang hari, naungan, posisi benih pada buah atau bunga, umur tanaman induk, serta suhu selama pembungaan (Copeland dan Donald, 2001). Wahyuni et al. (2004), menambahkan benih padi gogo varietas
Batutegi, Towuti, Situ Patenggang, Cirata, dan Limboto yang diproduksi di lahan sawah memberikan hasil dan mutu benih berupa viabilitas awal, viabilitas benih setelah disimpan, vigor awal dan vigor benih setelah disimpan yang lebih tinggi dibanding dengan benih padi gogo yang diproduksi di lahan kering pada musim hujan.

Selain itu, senyawa kimia inhibitor dapat menimbulkan efek negatif yang menghambat perkecambahan pada galur padi tersebut. Senyawa inhibitor ABA dan koumarin terdapat pada area aleuron, sekam, atau embrio benih padi. Pada proses pematangan, ABA mengalami peningkatan yang berbanding terbalik dengan IAA yang menurun pada benih padi (Sinambela, 2008). Dormansi benih padi perlu dipatahkan karena menimbulkan kerugian seperti pertumbuhan yang tidak serempak dan bergesernya ketepatan musim tanam. Tanpa didahului pematahan dormansi, pengujian daya berkecambah pada lot benih yang dormansi menyebabkan daya berkecambah benih tidak menggambarkan keadaan benih yang sebenarnya. Dormansi benih padi menyebabkan turunnya validitas daya berkecambah karena lot benih dinyatakan belum memenuhi syarat untuk sertifikasi dengan daya berkecambah yang dihasilkan di bawah $80 \%$. Adanya karakter dan jangka dormansi pada suatu benih juga dapat melengkapi deskripsi untuk kesiapan tanam dan perlakuan lainnya (Cempaka, 2011).

Perkecambahan benih padi memiliki karakteristik yang berbeda. Adanya faktor after ripening menunjukkan benih tidak dapat berkecambah ketika baru dipanen, melainkan setelah melewati masa penyimpanan kering. Menurut Ahmad (2010), after ripening merupakan perubahan pada kondisi fisiologis benih selama masa simpan yang mengubah benih menjadi mampu berkecambah. Periode after ripening ini berbeda-beda lamanya, mingguan, bulanan, bahkan tahunan tergantung jenih benihnya.

Dormansi benih mengalami beberapa fase hingga dapat melakukan perkecambahan. Menurut Khan (1977), awalnya benih mengalami fase induksi yang ditandai dengan terjadinya penurunan jumlah hormon pertumbuhan (ABA, sitokinin, dan giberelin). Ketika kadar ABA meningkat, benih akan memulai proses dormansi. ABA akan menekan hormon pertumbuhan lainnya, kemudian terjadi fase tertundanya metabolisme (a period of partial 
metabolic arrest). Akibat menurunnya kadar hormon pertumbuhan, benih tidak dapat merombak cadangan makanan pada endosperm, tidak ada hormon pertumbuhan yang menginduksi, sehingga metabolisme lemak tidak akan terjadi, yang selanjutnya terjadi fase bertahannya embrio untuk berkecambah karena faktor lingkungan yang tidak menguntungkan. Benih padi galur mutan (39e, 75d, 57e) memberikan respon fisiologis yang tidak berbeda berdasarkan nilai viabilitas dan vigor. Ketiga galur mutan ini menunjukkan daya atau kemampuan berkecambah yang tinggi sehingga sangat potensial untuk dikaji lebih lanjut dalam upaya perakitan varietas baru.

Perlakuan perendaman dalam air destilata berfungsi melarutkan senyawa inhibitor yang menghambat perkecambahan dan dapat melunakkan kulit benih. Perendaman merangsang penyerapan air lebih cepat (Ilyas dan Diarni, 2007). Perendaman benih dalam air dapat meningkatkan viabilitas potensial karena dapat menghilangkan fenol yang ada pada sekam padi sehingga oksigen dapat masuk ke dalam benih padi (Nugraha dan Soejadi, 2001). Perendaman benih dalam larutan $\mathrm{KNO}_{3} 3 \%$ meningkatkan daya berkecambah sampai $76 \%$, sedangkan perendaman benih dalam air meningkatkan pertumbuhan sampai $89 \%$ meskipun lebih lambat. Teknik pematahan dormansi menggunakan perendaman benih dalam larutan $\mathrm{KNO}_{3} 3 \%$ selama 24 jam merupakan teknik pematahan dormansi yang efektif untuk varietas Bah Butong, Lokal Batang, SL-8 dan Bernas Rokan. Perlakuan air sama efektifnya dengan perlakuan $\mathrm{KNO}_{3} 3 \%$ untuk mematahkan dormansi varietas Aek Sibundong dan TEJ (Cempaka, 2011).

Efektivitas $\mathrm{KNO}_{3}$ dalam mematahkan dormansi after ripening sangat tergantung pada respon fisiologis yang dibawa oleh masing masing galur, varietas, atau spesies padi. Informasi yang diperoleh dari penelitian ini sebagai rujukan bagi pemulia untuk dapat merakit varietas baru yang memiliki periode after-ripening yang lebih pendek. Bagi produsen benih atau analis benih dapat menggunakan teknik pematahan dormansi menggunakan perendaman benih dalam $\mathrm{KNO}_{3} 1-3 \%$ ataupun air destilata selama 24 jam.

\section{Kesimpulan}

1. Persistensi dormansi galur padi mutan adalah Sanbei Simeulu digolongkan kedalam persistensi panjang (8 minggu), galur mutan $75 \mathrm{~d}$ tergolong persistensi sedang (4 minggu) dan galur Sultan Unstrat, 39e, 57e tergolong persistensi pendek (3 minggu).

2. Galur padi mutan berpengaruh sangat nyata terhadap berat kering kecambah normal dan berpengaruh nyata terhadap potensi tumbuh maksimum. Galur padi mutan dengan nilai viabilitas dan vigor tertinggi adalah Sultan Unsrat dan 57e.

3. Konsentrasi $\mathrm{KNO}_{3}$ berpengaruh sangat nyata terhadap daya berkecambah dan berat kering kecambah normal, berpengaruh nyata terhadap potensi tumbuh maksimum dan kecepatan tumbuh relatif. Konsentrasi $\mathrm{KNO}_{3}$ terbaik adalah pada perlakuan 0-1\% berdasarkan nilai viabilitas dan vigor.

4. Interaksi antara faktor galur mutan dan konsentrasi $\mathrm{KNO}_{3}$ berpengaruh sangat nyata terhadap berat kering kecambah normal, berpengaruh nyata terhadap potensi tumbuh maksimum dan daya berkecambah. Interaksi terbaik dijumpai pada galur 57e dan konsentrasi $\mathrm{KNO}_{3} \quad 2 \%$ berdasarkan nilai potensi tumbuh maksimum dan daya berkecambah.

\section{Ucapan Terima Kasih}

Ucapan terima kasih kepada Rektor Universitas Syiah Kuala yang telah mendanai kegiatan penelitian ini melalui Penelitian Lektor Kepala PNBP Tahun 2018

\section{Daftar Pustaka}

Ahmad, A. 2010. Studi Pematahan Dormansi dan Periode After Ripening Padi Gogo Lokal Gorontalo. Tesis. IPB. Bogor.

Aisyah, S.I., H. Aswidinnoor, A. Saefuddin, dan B. Marwoto. 2009. Induksi Mutasi pada Stek Pucuk Anyelir (Dianthus caryophyllus Linn.) melalui Iradiasi Sinar Gamma. J. Agron. Indones. (Indonesian J. Agron. 37(1): 62-70. doi: 10.24831/jai.v37i1.1396

Bewley, J.D. and B. Michael. 1985. Seeds: Physiology of Development and Germination. New York: Plenum Press.

Cempaka, I.G. 2011. Periode after-ripening dan respon perlakuan pematahan dormansi pada benih padi merah dan padi hibrida (Oryza sativa L.). Tesis. IPB. Bogor 
Copeland, L.O and M.B. Donald. 2001. Principles of Seed Science and Technology. New York: Chapman and Hall.

Crowder, L.V. 1986. Genetika Tumbuhan. Gadjah Mada University Press. Jogjakarta.

Gu, X.-Y., Z.-X. Chen, and M.E. Foley. 2003. Inheritance of Seed Dormancy in Weedy Rice. Crop Sci. 43: 835-843. doi: 10.2135/cropsci2003.8350.

Ilyas, S., and W. Diarni. 2007. Persistensi dan Pematahan Dormansi Benih pada Beberapa Varietas Padi Gogo. J. Agrista 11(2): 92-101.

International Seed Testing Ascotiation (ISTA). 1999. International rules for seed testing. seed science and technology. international seed testing association. Zurich Switzerland.

Kharismayani, I. 2010. Kajian After Ripening Pada Beberapa Varietas Benih Padi Gogo. Teis. IPB. Bogor.

Khan, A.A. 1977. Physiology and Biochemistry of Seeds in Relation to Germination. North Holland, Amsterdam.

Nugraha, U., dan Soejadi. 2001. Studi Efikasi Metode Pematahan Dormansi Benih Padi.
Buletin Penelitian Pertanian Tanaman Pangan 20 (1) : 72 - 79.

Ooi, M., T. Auld, and R. Whelan. 2007. Distinguishing between persistence and dormancy in soil seed banks of three shrub species from fire-prone southeastern Australia. J. Veg. Sci. 18: 405-412. doi: $10.1658 / 1100-$ 9233(2007)18[405:DBPADI]2.0.CO;2.

Poehlman, J.M. and D.A. Sleper. 2006. Breeding Field Crops. $5^{\text {th }}$ edition. Wiley-Blackwell

Santika, A. 2006. Teknik Pengujian Masa Dormansi Benih Padi (Oryza sativa L.). J. Bul. Tek. Pertan. 11(25): 67-71. http://203.190.37.42/publikasisummary.php?contentID=bt112067

Sinambela, D. 2008. Kajian Perkembangan dan Dormansi Pada Biji Padi (Oryza sativa L.). Tesis. USU. Medan.

Wahyuni, S., U.S. Nugraha, dan Soejadi. 2004. Karakterisasi Dormansi dan Metode Efektif untuk Pematahan Dormansi Benih Plasma Nutfah Padi. Penelitian Pertanian Tanaman Pangan. 23(2):73-78. 